\section{O histórico de criação da Agência Nacional de Assistência Técnica e Extensão Rural (ANATER) e os desafios impostos a sua consolidação na conjuntura política de 2017}

Carolina Rios Thomson

Sonia Maria Pessoa Pereira Bergamasco ${ }^{2}$ Ricardo Serra Borsatto

Resumo: O objetivo deste trabalho é, primeiramente, compreender os arranjos institucionais e o comportamento dos diferentes agentes nos espaços de debate e gestão do estado brasileiro no cenário em que se deu a criação da Agência Nacional de Assistência Técnica e Extensão Rural (ANATER) em 2013. Em segundo lugar, buscamos analisar em que medida o fim da gestão do Partido dos Trabalhadores no executivo federal em 2016 passou a afetar sua implementação. A metodologia baseou-se em revisão bibliográfica, entrevistas semiestruturadas e resultados preliminares da pesquisa "Evaluation of Extensin Reforms in Brazil". Concluímos que, de 2003 a 2016, as políticas de Assistência Técnica e Extensão Rural (ATER) para a agricultura familiar foram marcadas por inovações e avanços no campo político institucional, especialmente em relação à participação social na gestão e controle das mesmas. A criação da ANATER marcou uma importante conquista para a consolidação das políticas de ATER no Brasil, apesar das críticas ao processo de sua concepção. No entanto, no cenário político e institucional de 2016 e início de 2017, a ANATER e seus gestores se distanciaram dos objetivos iniciais e dos atores políticos vinculados a este processo, o que traz à tona a permanente fragilidade de políticas de ATER para a agricultura familiar, apesar dos avanços identificados.

Palavras-chave: Agricultura Familiar; Políticas Públicas; Agroecologia.

\footnotetext{
Mestre em Agroecologia e Desenvolvimento Rural pela Universidade Federal de São Carlos (2014). Doutoranda em Ciências Sociais pela Universidade Estadual de Campinas. Integra a equipe de coordenação da Rede UFSCar Agroecológica, da Universidade Federal de São Carlos.

${ }_{2}^{2}$ Professora titular da Universidade Estadual de Campinas e da Universidade Federal de São Carlos.

${ }^{3}$ Mestre em Desenvolvimento Rural Sustentável da Universidade Federal do Paraná (2007) e Doutor pela linha de Planejamento e Desenvolvimento Rural Sustentável do programa de Pós-Graduação em Engenharia Agrícola da
} Universidade Estadual de Campinas (2011). É professor adjunto da Universidade Federal de São Carlos.
Abstract: This paper presents a historical review concerning the institutional context and behavior of different agents in public spheres of debate and management from the Brazilian state during the implementation and execution of the National Policy of Technical Assistance and Rural Extension (PNATER). Such rescue is a subsidy for the analysis of the scenario in which the National Agency for Technical Assistance and Rural Extension (ANATER) has been created in 2013, as for to understand in which extent the end of the Labors' Party rule in the federal executive and the extinction of the Ministry of Agrarian Development (MDA) in 2016 have affected its implementation. Finally, we draw a comparative parallel between the recent political scenario for technical assistance and rural extension policies and that of the early 1990s to demonstrate common ground that can be identified in the neoliberal agenda in both political scenarios.

Keywords: Family Farming; Public Policies; Agroecology.

\section{Introdução}

A retomada das discussões em nível nacional de políticas públicas de Assistência Técnica e Extensão Rural (ATER) foi possível a partir da ascensão ao poder do Partido dos Trabalhadores em 2002. A inauguração da denominada Nova Ater brasileira tem como marco o lançamento da primeira versão da PNATER (Política Nacional de Assistência Técnica e Extensão Rural) em 2003, sendo fruto da mobilização da Sociedade Civil somada ao contexto político de abertura à participação democrática de um governo historicamente ligado aos movimentos sociais de esquerda, bem como ao engajamento de gestores públicos comprometidos com um modelo de desenvolvimento rural baseado na agricultura familiar.

Porém, sua concepção remonta à década de 1990, quando, após a extinção da Empresa Brasileira de Assistência Técnica e Extensão Rural (EMBRATER), organizações da Sociedade Civil como a Federação Nacional do Trabalhadores da Assistência Técnica e do Setor Público Agrícola do Brasil (FASER), Organizações Não Governamentais (ONGs) ligadas à agricultura familiar, associações e cooperativas de agricultores, movimentos sociais do campo e a Associação Brasileira de Empresas de Extensão Rural (ASBRAER), estabeleceram e mantiveram fóruns para a discussão e exercício de pressão política em nome de uma ATER pública no Brasil.

Todavia, a recente implementação da Agência Nacional de Assistência 
Técnica e Extensão Rural (ANATER), em 2013, apresenta novas perspectivas para os serviços públicos de ATER no Brasil. Desde sua idealização, não há consenso entre os envolvidos em sua concepção, nem entre aqueles que passarão a ser atendidos pelo novo modelo de ATER, em relação às diretrizes, público beneficiário e forma de gestão da Agência.

Por estes motivos, a criação e implementação da ANATER merecem ser amplamente estudadas e discutidas não apenas do ponto de vista acadêmico, mas também junto aos atores que vêm contribuindo e serão afetados por sua consolidação. Diante das polêmicas que rondam a ANATER, acredita-se que a análise dos discursos, estratégias e papéis desempenhados pelos gestores públicos, movimentos sociais, organizações de agricultores e profissionais da extensão rural envolvidos neste processo, são importantes subsídios às discussões acerca dos modelos de desenvolvimento rural no país e sua relação com a agricultura familiar.

\section{Metodologia}

O presente artigo pretende compreender a construção histórica dos arranjos institucionais que permearam as políticas públicas de ATER no Estado brasileiro e que, em 2017, materializam-se na criação da ANATER - ainda não implementada de fato. Para tanto, parte do pressuposto de que a consolidação de instituições formais e de seus instrumentos de poder podem resultar em transformações profundas da estrutura social e, neste caso em especial, da realidade de agricultores e extensionistas rurais.

Para tratar da criação da ANATER, uma breve introdução do contexto macro político das década de 1990, 2000 e início dos anos 2010 são apresentados, a fim de relacioná-lo com as diretrizes das organizações responsáveis pelas políticas de ATER no período, bem como compreender em que condições se deram as negociações entre os diferentes atores envolvidos na elaboração e execução destas políticas - sejam estes atores inseridos na máquina pública, movimentos sociais, classe patronal ou outras entidades da Sociedade Civil. Neste sentido, a análise atribuirá maior destaque às instituições do que ao voluntarismo individual de seus gestores, podendo, no entanto, reconhecer o contrário em situações pontuais.

\section{A extinção da Empresa Brasileira de Assistência Técnica e Extensão Rural (EMBRATER)}

O Plano Nacional de Desenvolvimento (1972-1974) do governo militar incluiu dentre suas prioridades amplos investimentos em Ciência e Tecnologia. Neste contexto, em 1972 foi criada a Empresa Brasileira de Pesquisa Agropecuária (EMBRAPA), atrelada ao Ministério da Agricultura, com vistas a levar adiante um programa nacional de pesquisa e experimentação agropecuária voltado à geração e adequação de tecnologias para a modernização agrícola, relacionada principalmente à adaptação de maquinário e insumos químicos, dentre os quais fertilizantes, corretivos e defensivos agrícolas.

Dois anos depois, em 1974, foi instituída a Empresa Brasileira de Assistência Técnica e Extensão Rural (EMBRATER) (BERGAMASCO, 1983). Determinou-se que a EMBRATER e a EMBRAPA deveriam executar suas atividades de forma integrada e apoiar financeiramente instituições estaduais de extensão e pesquisa. Este período é considerado o marco da consolidação do difusionismo produtivista na ATER brasileira, dada a estreita associação entre a EMBRAPA, por meio da produção dos denominados pacotes tecnológicos, a EMBRATER, responsável por sua disseminação, e o Sistema Nacional de Crédito, que através do Banco do Brasil garantiu o financiamento às tecnologias anteriormente mencionadas.

O plano de trabalho da EMBRATER dividiu-se em duas principais linhas de ação, com públicos específicos. De um lado, a difusão de tecnologia e conhecimento gerenciais voltaram-se aos produtores de média e alta renda, que se tornaram os principais responsáveis pelo aumento da produtividade nacional e ampliação das exportações agrícolas. O segundo público tratava-se dos produtores de baixa renda, aos quais a estratégia proposta delimitara-se à adoção de pacotes tecnológicos simplificados via crédito e à venda do excedente às cooperativas locais ou Companhia Brasileira de Alimentos (Cobal). Aos primeiros, portanto, coube o protagonismo da modernização agrícola e os louros dos superávits da balança comercial brasileira. Aos segundos, por outro lado, o papel de coadjuvantes, responsáveis pelo abastecimento interno, sob a condição de manter um nível de autossuficiência econômica mínimo mediante as condicionalidades dos empréstimos contratados.

Dados de 1979 demonstram que houve clara seleção do público atendido pelos serviços de ATER do período. Apenas 16\% do total de produtores brasileiros (ambos os públicos) foi atendido e, no caso do crédito agrícola, menos de $15 \%$ do total disponibilizado foi acessado por pequenos produtores (BERGAMASCO, 1983). Assim, as ações de desenvolvimento rural levadas 
a cabo pelo governo brasileiro nas décadas de 1970 e 1980 foram, sem dúvidas, bem-sucedida na consolidação da denominada modernização conservadora (PASSOS GUIMARÃES, 1968) do campo brasileiro, por meio da formação de uma classe de empresários rurais altamente capitalizados e do aumento subsidiado da produtividade agrícola nacional.

Por outro lado, houve a crescente exclusão da agricultura de base familiar no acesso às políticas de crédito e ATER, bem como consequente concentração de terras e rendas no campo. Isto porque, as políticas adotadas resultaram na insustentabilidade das "pequenas" produções, num cenário de queda dos preços dos produtos agrícolas, subordinação aos circuitos longos de comercialização e especulação fundiária. No entanto, o discurso governamental do início de década de 1980 proclamava que a modernização agrícola havia sido bem-sucedida e que o Brasil havia se tornado o "celeiro mundial".

Tal modelo levou à migração massiva de populações rurais para os centros urbanos em busca de empregos e renda, decorrendo numa grave crise social que, somada à crise inflacionária e vertiginoso aumento da dívida externa, pôs em cheque as políticas de governo adotadas durante as décadas anteriores. Como resultado das pressões da Sociedade Civil organizada, em 1980 o Ministério da Agricultura passou a determinar que mais agricultores fossem atendidos por técnicos de ATER, dentre os quais pequenos e médios agricultores, bem como que a abordagem incluísse novamente a qualidade de vida da família rural. Porém, como aponta Pettan (2010), a aproximação das diretrizes de ATER às questões de cunho social teriam sido menos voluntarismo governamental do que, em verdade, uma tentativa da EMBRATER de se legitimar no processo de reabertura democrática.

Após a eleição de Tancredo Neves em 1985, ascendem aos cargos executivos profissionais alinhados a correntes progressistas indicados antes de sua morte. Estes nomes foram acatados, em um primeiro momento, por aquele que efetivamente tornou-se presidente de república, José Sarney. Dentre estes profissionais, encontrava-se o extensionista Romeu Padilha de Figueiredo, que assumiu a presidência da EMBRATER. Na cerimônia de sua posse, anunciou que a extensão rural priorizaria os pequenos e médios agricultores, em diálogo com as diretrizes do primeiro Plano Nacional de Desenvolvimento da Nova República (I PND-NR), que estabeleceu a dívida social como prioridade de governo, e com a carta do $4^{\circ}$. Congresso da Confederação Nacional dos Trabalhadores da Agricultura (CONTAG), realizado meses antes (PETTAN, 2010). A EMBRATER passou a incorporar também o apoio à formação de organizações de agricultores e a adoção de práticas ecológicas.

A partir de então, a Sociedade Civil organizada teve ampla participação na construção de uma nova visão da ATER, principalmente através da atuação da FASER, das Comunidades Eclesiais de Base, da CONTAG, do Movimento dos Trabalhadores Rurais Sem Terra (MST), de Organizações não governamentais (ONGs), das organizações de trabalhadores rurais e de outros movimentos sociais do campo (PETTAN, 2010). Rodrigues (1997) e Pettan (2010) apontam que neste período predominou o humanismo crítico na ATER brasileira, que pauta o empoderamento dos agricultores familiares e o papel do Estado como parceiro e, ao extensionista, o diálogo horizontal e democrático.

A crítica ao difusionismo produtivista e à modernização agrícola baseouse principalmente na exclusão dos sujeitos historicamente marginalizados e na transferência vertical da tecnologia gerada pela EMBRAPA. Em relação ao histórico da ATER, avaliou-se que pequenos agricultores, lavradores, posseiros e populações tradicionais sempre foram vistos como ignorantes e seus conhecimentos como rudimentares, atrasados. A nova proposta baseouse amplamente na visão Freireana de valorização dos saberes locais e na construção coletiva de soluções, capitaneadas pelos próprios agricultores, sendo o extensionista intermediador deste processo.

No entanto, a existência da EMBRATER passou então a ser crescentemente ameaçada junto ao governo, no qual a ampla maioria dos gestores detinha a convicção de que a modernização agrícola havia sido bem-sucedida e que, portanto, a assistência técnica deveria limitar-se à prestação de serviços privados futuramente. De acordo com esta visão, caberia ao Ministério da Agricultura priorizar seus recursos para programas de comercialização e crédito agrícola voltados aos produtores já integrados ao mercado.

Assim, em 1986, o governo Sarney passou a pautar a necessidade urgente de reformas institucionais, que, na prática, traduziam-se no enxugamento da máquina pública e especialmente das empresas que não geravam divisas ao patrimônio nacional. Os ministérios da Fazenda e da Administração assumiram o protagonismo deste processo, através da articulação da denominada Operação Desmonte, que preconizava a extinção de ministérios, autarquias e empresas federais. Uma série de tentativas de 
fusão da EMBRATER à EMBRAPA foram empreendidas neste contexto, porém entidades como FASER e CONTAG, com o apoio de congressistas alinhados a movimentos sociais, impediram as investidas do governo federal.

No entanto, após a eleição em 1989 do presidente Fernando Collor e da eleição de um Congresso Nacional majoritariamente alinhado aos partidos de direita no mesmo período, a extinção de serviços públicos considerados onerosos e não essenciais ao Estado se concretizou. O Estado assumiu assim, a partir deste momento, a função de gestor ao invés de executor do desenvolvimento nacional. A EMBRATER e outras estatais foram extintas por decreto em 1990 e, sem o apoio do Congresso Nacional, as organizações da Sociedade Civil não encontraram o apoio político necessário ao revés destas ações.

Após a extinção da EMBRATER, cessaram os repasses federais às empresas estaduais de ATER e, como consequência, em vários estados ocorreram extinções, em outros, fusões e, naqueles em que o serviço continuou a ser prestado, o sucateamento das empresas estaduais. A coordenação do Sistema brasileiro de ATER foi transferida à EMBRAPA e a regulamentação e prestação dos serviços de ATER circunscritas ao Instituto Nacional de Colonização e Reforma Agrária (INCRA) (PEIXOTO, 2008), que atua exclusivamente em áreas de Reforma Agrária.

A EMBRAPA, porém, por não dispor do savoir-faire, recursos e pessoal necessários à sua nova responsabilidade não foi bem-sucedida na manutenção dos serviços de ATER. Ademais, como apontado anteriormente, por ter desde sua criação como principal competência a pesquisa agropecuária com a finalidade de produzir pacotes tecnológicos para a transferência vertical de tecnologia, teve pouco diálogo com a extinta EMBRATER. A EMBRAPA também se manteve distante dos debates ocorridos junto à Sociedade Civil durante os anos de 1983 e 1989, nos quais foram profundamente discutidas as relações entre produção de conhecimento participativo, ATER, reformas estruturais e o papel da agricultura familiar no desenvolvimento rural.

Em 1990 a Associação Brasileira das Entidades Estaduais de Assistência Técnica e Extensão Rural (ASBRAER) foi criada por dirigentes de empresas estaduais de ATER, numa tentativa de manter a articulação entre as entidades. Porém, devido às restrições da coordenação do Sistema brasileiro de ATER via EMBRAPA e ao impacto drástico nos orçamentos das entidades, o desmembramento do sistema foi inevitável.

Neste cenário, ONGs, sindicatos e organizações de agricultores, como cooperativas e associações, passaram a protagonizar experiências regionais de ATER. Paralelamente, empresas comerciais de insumos agrícolas e maquinário também assumiram este papel, enviando seus técnicos às propriedades e prestando assistência técnica através da recomendação de receituário e uso de seus produtos.

Desde o início da década de 1990, também ocorria a disseminação dos princípios agroecológicos entre importantes ONGs de extensão rural que teve, entre outras consequências, a projeção da Agroecologia como movimento social a partir da rearticulação das bases do movimento da Agricultura Alternativa no Brasil (LUZZI, 2007 e BRANDEBURG, 2002). Estas organizações passaram a adotar princípios e metodologias da Agroecologia no final de década de 1980, através de uma abordagem que preza pelo estímulo aos mercados locais, valorização do saber e tecnologias tradicionais na produção de base ecológica, estratégias de soberania alimentar, preservação de sementes crioulas, entre outras questões (LUZZI, 2007).

Em relação às lutas pela Reforma Agrária, o MST protagonizou uma série de ocupações em latifúndios e prédios públicos também neste período, tendo sido violentamente reprimido pelas forças policias e grupos armados particulares financiados por aqueles que alegavam deter a propriedade das terras ocupadas. Dois massacres ganharam grande visibilidade tanto internacional como nacional, sendo estes o de Corumbiara (RO) em 1995 e o de Eldorado dos Carajás (PA) em 1996, e, assim, diante da crescente pressão dos movimentos sociais, o governo de Fernando Henrique Cardoso passou a constituir espaços formais de diálogo para negociação. Em 1996, foi então instituído o Programa Nacional de Fortalecimento da Agricultura Familiar (PRONAF), que destoou do segmento de políticas usuais do setor agrícola.

De acordo com Peixoto (2008), o debate em torno da proposta de estabelecimento de uma ATER pública e universal tomou corpo durante o "Seminário Nacional de Assistência Técnica e Extensão Rural - Uma nova extensão para a agricultura familiar", ocorrido em agosto de 1997 na capital federal e organizado pela FASER, CONTAG, ASBRAER, com o apoio do Governo Federal. No evento, foram retomadas as discussões acerca dos princípios e diretrizes da ATER pública, no sentido do humanismo crítico e do movimento agroecológico, bem como propostas para sua operacionalização. Nos três meses subsequentes ocorreram seminários sobre o mesmo tema em todas as unidades da federação, dos quais participaram cerca de cinco mil pessoas interessadas, principalmente extensionistas, 
agricultores familiares, sindicalistas e pesquisadores.

Em novembro, foi então realizado o "Workshop" Uma Nova Assistência Técnica e Extensão Rural Centrada na Agricultura Familiar, organizado pela FASER, CONTAG, ASBRAER, MAA e Programa das Nações Unidas para o Desenvolvimento (PNUD). Do evento resultou a proposição de um modelo de ATER voltado exclusivamente à agricultura familiar, gratuito aos beneficiários e financiado com recursos públicos, mas no qual pudessem prestar os serviços tanto ONGs, como associações e cooperativas de agricultores, além de empresas e outras entidades públicas. Ademais, seus princípios apontavam o pluralismo na prestação de serviços, para que pudessem ser incluídas e respeitadas as singularidades das populações tradicionais, indígenas e quilombolas (WORKSHOP, 1997).

A proposta concebida no Workshop ainda levaria anos para se concretizar, no entanto, suas atividades foram fundamentais para a mobilização de uma extensa rede de atores que atuavam com extensão rural pelo país. De acordo com Peixoto (2008), a maior resistência aos pontos discutidos no evento se deu, na prática, por parte dos técnicos das empresas públicas, que em grande medida mantiveram seus trabalhos junto à agricultura patronal, voltados à modernização agrícola convencional.

Peixoto (2008) também destaca que em 1997 ocorreu a primeira experiência de terceirização de serviços de ATER pelo Estado, através do projeto Lumiar coordenado pelo INCRA e, portanto, voltado aos assentamentos da Reforma Agrária. O projeto atendeu mais de cem mil famílias, apesar de cancelado pelo governo em 2000.

Ao fim de 1999 até janeiro de 2000, uma série de decretos levou à criação do Ministério do Desenvolvimento Agrário (MDA). Em sua estrutura, foi estabelecido o Conselho Nacional de Desenvolvimento Rural Sustentável (CNDRS), com representatividade de gestores públicos e sociedade civil, tendo sido garantido à ASBRAER uma de suas quinze cadeiras.

Além do CNDRS, foram instituídas a Secretaria de Reforma Agrária e a Secretaria da Agricultura Familiar (SAF), responsáveis respectivamente pelas políticas de crédito, pesquisa, assistência e extensão nos assentamentos e para a agricultura familiar. No entanto, a coordenação do Sistema brasileiro de ATER continuou a cargo do então Ministério da Agricultura e Abastecimento (MAA). Em 2000 foi extinta, na estrutura do MAA, a Secretaria de Desenvolvimento Rural (SDR) e o Departamento de ATER (DATER), tendo sido criada a Secretaria de Apoio Rural e Cooperativismo
(SARC), na qual foi instituído o Departamento de Infraestrutura e Extensão Rural (DIER), que assumiu a coordenação do sistema. No ano de 2001 o MAA foi transformado em Ministério da Agricultura, Pecuária e Abastecimento (MAPA). Após este reordenamento, as políticas de ATER passaram a ser consideradas atribuições tanto do MAPA, via DIER, como do MDA, via Secretaria da Agricultura Familiar (SAF). Neste último, porém, o público beneficiário era específico: a agricultura familiar.

As eleições de 2002 representarem uma guinada em termos de abertura para a consolidação de políticas baseadas na ampla participação da Sociedade Civil. A vitória do Presidente Luis Inácio Lula da Silva, do Partido dos Trabalhadores (PT), marcou a ascensão do primeiro governo de esquerda ao executivo federal desde a restauração das eleições diretas, em 1989. A partir de então, os agricultores familiares passaram a ser beneficiários de importantes políticas públicas.

Em 13 de junho de 2003, o Decreto $n^{\circ} 4.739$ transferiu a competência da execução de serviços públicos de Assistência Técnica e Extensão Rural do DIER/MAPA para o MDA e, portanto, a coordenação do Sistema Brasileiro de ATER. Meses depois, o Decreto $\mathrm{n}^{\circ} 4.854$ de 8 de outubro de 2003 criou o Conselho Nacional de Desenvolvimento Rural, Reforma Agrária e Agricultura Familiar (CONDRAF), que incorporou a agricultura familiar ao nome do antigo CNDRS. Este órgão é composto paritariamente por representantes da Sociedade Civil organizada e do poder público executivo. O CONDRAF, sob coordenação do MDA, teve por finalidade propor diretrizes para formular, implementar e avaliar políticas públicas de ATER a partir da ampla participação social (MDA/SAF/DATER, 2004).

Então, o MDA passou a organizar uma série de seminários junto a representantes de entidades não governamentais, instituições dos governos estaduais, organizações de agricultores familiares e movimentos sociais, a fim de consolidar políticas públicas que privilegiassem a agricultura familiar para além do estabelecido no PRONAF. Nestes encontros foram discutidas estratégias para que a ATER pública abarcasse toda a diversidade da agricultura familiar no país, com linhas de ação em políticas de gênero, etnia, juventude, educação e Agroecologia.

Em maio de 2004, o Governo Federal lançou a Política Nacional de Assistência Técnica e Extensão Rural (PNATER), como resultado destes fóruns junto à Sociedade Civil. No documento encontram-se elencadas as diretrizes e princípios para a ATER no país, incluindo as metodologias 
e princípios propostos pela Agroecologia para o desenvolvimento de trabalhos, a determinação de seu público prioritário como as agricultoras e os agricultores familiares e a caracterização do serviço a ser prestado como gratuito e universal (BRASIL, 2004).

Também em 2004, o decreto $\mathrm{n}^{\mathrm{o}} 5.033$ de 5 de abril aprovou a estrutura Regimental do MDA e institui o Departamento de Assistência Técnica e Extensão Rural (DATER), sob administração da Secretaria de Agricultura Familiar (SAF). Ao novo DATER coube elaborar, junto à Sociedade Civil, um programa de governo que operacionalizasse as propostas contidas na PNATER. O INCRA, paralelamente, criou o programa Serviço de Assessoria, Assistência Técnica, Social e Ambiental à Reforma Agrária (ATES), que permitiu novamente a terceirização da ATER em Assentamentos da Reforma Agrária. Na SARC/MAPA, a ATER continuou a configurar dentre suas atribuições, porém quando o DIER foi transformado em Departamento de Infraestrutura e Logística em 2005, sequer foi atribuído especificamente a outro órgão da Secretaria a competência das atividades relativas à ATER (PEIXOTO, 2008)

Em 2005 foi lançado o Programa Nacional de Assistência Técnica e Extensão Rural na Agricultura Familiar e na Reforma Agrária (PRONATER), na qual foram elencadas metas e ações específicas de incentivo a programas estaduais de ATER, capacitação de agricultoras e agricultores familiares, formação de quadros para a ATER Setorial (trabalhos junto às comunidades indígenas, quilombolas, ribeirinhos, pescadores artesanais, aqüicultores, extrativistas, jovens e mulheres trabalhadoras rurais) e de qualificação e ampliação dos serviços de ATER no país (MDA/SAF/DATER, 2004).

Além das políticas de ATER voltadas aos executores e beneficiários diretos, o PRONATER também previu recursos para parcerias com o Conselho Nacional de Desenvolvimento Científico e Tecnológico (CNPq) direcionadas às instituições de ensino e pesquisa, com intuito de ampliar a formação de quadros técnicos e o desenvolvimento de tecnologias para atender à agricultura familiar.

Em 2006, por meio da Portaria Ministerial no 25, o Governo Federal formalizou a operacionalização do Sistema Brasileiro de Assistência Técnica e Extensão Rural (SIBRATER) que se tornou, a partir de então, descentralizado. O MDA, em parceria com outros Ministérios, Secretaria Especiais, INCRA e/ou empresas públicas, passou a ser o órgão federal responsável pelo repasse de recurso público da União às organizações de
ATER no país (BRASIL, 2010).

As principais inovações na concepção do novo SIBRATER resgataram a proposta do Workshop de 1997, cabendo destacar o estabelecimento de uma articulação em rede, por meio de organizações públicas ou privadas de ATER e representações de movimentos sociais, bem como o estabelecimento da metodologia de trabalhos por territórios, ao invés de divisões regionais ou estaduais. Além destes pontos, o controle da execução dos serviços de ATER privilegiou a participação das representações das comunidades a serem beneficiadas pelo PRONATER no controle e avaliação dos trabalhos executados

Ao longo dos anos subsequentes, esta rede de atores identificou uma série de entraves ao cumprimento bem-sucedido das diretrizes da PNATER e metas do PRONATER. Dentre estes, a burocracia exigida para a eligibilidade das entidades às licitações de ATER, especialmente no caso de ONGs ou associações e cooperativas de agricultores familiares, devido aos trâmites exigidos para prestação de contas e condições para o pagamento dos serviços profissionais.

Até então, os serviços de ATER enquadravam-se na Lei de nº 8.666 de 21 de junho de 1993, mais conhecida como Lei de Licitações, que veda o pagamento antecipado de serviços e exige que os comprovantes e atestes de sua realização sejam formalmente encaminhados para pagamento posterior. Tais condições reduziam as possibilidades de entidades sem considerável aporte de capital ampliarem sua atuação e/ou prejudicava a dinâmica e qualidade dos trabalhos nos contratos com a administração pública. Ademais, organizações de ATER costumam ser caracterizadas por quadros de pessoal reduzidos, portanto a dinâmica imposta pelos contratos com a Administração Pública terminava por sobrecarregar os profissionais de campo, comprometendo a qualidade e continuidade de seus trabalhos.

Em 2010 foi por fim aprovada pelo Congresso Nacional e sancionada pelo Presidente da República a Lei 12.188, ou Lei de ATER, bem como lançada uma nova versão da PNATER e do PRONATER. Apesar de muitas críticas, como podem ser observadas nos trabalhos de Diniz et al. (2011) e de Caporal (2011), sua publicação representou um avanço político no que diz respeito à consolidação de um modelo de ATER pública voltado à agricultura familiar, assim como certa independência em relação às alternâncias de governo.

A Lei de ATER também desvinculou a contratação dos serviços de ATER da Lei de licitações, passando a dispensar a realização das mesmas para a seleção de instituição ou organização, pública ou privada, com ou sem 
fins lucrativos. Os serviços passaram assim a ser contratados mediante a modalidade de Chamadas Públicas e nos contratos firmados tornouse possível o pagamento às entidades após apresentação de relatório de realização de serviço, ocorrendo apenas posteriormente o processo de fiscalização por meio da apresentação de atestes.

Cabe destacar que a nova lei não resolveu todas as dificuldades enfrentadas por considerável parcela das organizações de ATER, apesar do aumento substancial dos recursos federais para o financiamento dos serviços e da nova modalidade de contratação. Permanece como importante dificuldade das menores entidades privadas de ATER a execução das atividades iniciais em seus projetos. Isto porque, os contratos com a administração pública ainda não permitem o adiantamento do pagamento de serviços profissionais, mas apenas de uma taxa de mobilização para a compra de materiais, equipamentos e custeio de atividades.

Ademais, as empresas estaduais de ATER permanecem dependentes dos governos estaduais para o pagamento de pessoal e, em alguns estados, também dos governos municipais para alocação física de suas entidades, ao passo que a execução da maioria de suas atividades tem sido financiada pelas Chamadas Públicas. Neste contexto, a competição entre entidades do terceiro setor e empresas estaduais tem se demonstrado um percalço à articulação bem-sucedida do SIBRATER

Aponta-se também o aparecimento de associações que operam numa lógica empresarial, as quais vêm se apropriando de parte significativa dos recursos federais destinados à ATER. Organizações estas que não possuem compromisso histórico com as diretrizes dos programas de ATER, se assemelhando muito com empresas terceirizadoras de mão de obra qualificada.

A Lei de ATER prevê a realização de conferências territoriais estaduais e nacional junto a representantes do público beneficiário, movimentos sociais e às entidades de ATER, a fim de operacionalizar a PNATER por meio do PRONATER nos períodos subsequentes. A Conferência Nacional de Ater (CNATER) deve ocorrer a cada quatro anos e, a partir das metas do PRONATER, o MDA encaminha o orçamento para inserção no Plano Plurianual (PPA), sendo o mesmo passível de cortes e emendas pelo Congresso Nacional, ou veto do Presidente da República. A primeira CNATER ocorreu em 2012, na qual foi discutida a necessidade do reestabelecimento de um órgão nacional de ATER. A segunda CNATER ocorreu em 2016, após o afastamento da presidente Dilma Roussef da presidência da república e na qual era real a perspectiva de extinção do MDA com a assunção de Michel Temer à presidência. Extinção esta que, um mês depois, se concretizou.

\section{A criação da ANATER}

Dentre as vantagens apontadas na primeira CNATER para o estabelecimento de uma instituição responsável pela coordenação da execução das políticas ATER em nível nacional, destacava-se a possibilidade de mais recursos e pessoal para a realização do serviço. Assim, a partir de 2012, formou-se uma comissão no âmbito do MDA que passou a discutir uma proposta a ser encaminhada ao Congresso Nacional para o estabelecimento de um órgão federal responsável pela coordenação executiva e financeira das atividades de ATER no país. Nas reuniões da comissão participaram gestores públicos, FASER, ASBRAER, FETRAF, CONTAG, além de acadêmicos dedicados à temática da extensão rural.

Paralelamente, outra equipe coordenada pelo MAPA, da qual participaram gestores da EMBRAPA, Conselho Nacional dos Sistemas Estaduais de Pesquisa Agropecuária (CONEPA) e a Confederação Nacional da Agricultura (CNA), também passou a elaborar uma proposta para a criação de um órgão nacional de ATER. A partir de sua apresentação ao $M D A$, foi suscitado intenso diálogo entre a SAF, o DATER e o Departamento de Transferência de Tecnologia (DTT) da EMBRAPA. Após as negociações, decidiu-se pelo estabelecimento de um Serviço Social Autônomo, denominado Agência Nacional de Assistência Técnica e Extensão Rural (ANATER). Assim, o Projeto de Lei $n^{\circ}$ 5740/2013, que trata da criação de ANATER, foi assinado pela Presidente da República no lançamento do Plano Safra para a agricultura familiar, em 6 de junho de 2013, e encaminhado ao Congresso Nacional em 10 de junho.

No documento original, constavam três órgãos de direção da ANATER, sendo estes a Diretoria Executiva, o Conselho de Administração e o Conselho Fiscal. No caso do Conselho de Administração, o mesmo deveria ser composto pelo Presidente da ANATER, a ser nomeado pela presidência da república, pelo Presidente da Embrapa, por cinco representantes do Poder Executivo e quatro de entidades privadas. Ademais, um dos membros da Diretoria Executiva deveria ser obrigatoriamente o Diretor-Executivo da EMBRAPA, que detivesse atribuição para atuar na área de transferência 
de tecnologia.

O projeto de lei conferia claro protagonismo na coordenação da ANATER à EMBRAPA, que desfrutaria de cadeiras tanto no Conselho de Administração como na Diretoria Executiva, para exercer especificamente atividades de transferência de tecnologia. No mais, não constavam na proposta referências à Agroecologia. Em reação, o movimento agroecológico elaborou uma carta de repúdio à criação da ANATER durante o III Encontro Internacional de Agroecologia (EIA), que ocorreu em agosto de 2013 (ENCONTRO INTERNACIONAL DE AGROECOLOGIA, 2013).

No documento consta que os participantes do III EIA discordavam do modelo de gestão proposto, pois "a maior parte do acervo tecnológico desenvolvido pelo SNPA não se ajusta à realidade da agricultura familiar, povos e comunidades tradicionais por induzi-los à crescente dependência ao sistema financeiro e agroindustrial", assim como porque "a perspectiva agroecológica não se coaduna com a intenção de disseminação universal de tecnologias geradas em meio controlado nos centros de pesquisa". Em contrapartida, delegavam que, em lugar do modelo difusionista, o sistema de ATER mantivesse as "abordagens para construção do conhecimento fundamentadas na ação protagonista das comunidades rurais em parceria com extensionistas e pesquisadores".

Além destas críticas, dentre as principais polêmicas em relação ao Projeto de Lei, naquele momento em tramitação no Congresso Nacional, cabem destacar a questão do público prioritário para a contratação dos serviços de ATER, que deixaria de ser unicamente destinado aos agricultores familiares; a composição da coordenação do SIATER, na qual não havia sido garantida a presença de representantes do Sociedade Civil ligados à agricultura familiar; e a capacitação dos extensionistas, que ficaria a cargo do Departamento de Transferência de Tecnologia da EMBRAPA. Dentes estas, as principais preocupações dos movimentos sociais e rede de ATER relacionavam-se à garantia exclusiva da prestação de serviços aos agricultores familiares, e à manutenção dos princípios do humanismo crítico, que vinham norteando a extensão rural brasileira desde a primeira versão da PNATER.

A atuação da FASER junto aos parlamentares foi decisiva durante o trâmite do projeto de lei para que o documento pudesse ser modificado nestes pontos fundamentais. Assim, durante a apreciação do PL 5740/2013 foram apresentadas 41 emendas pela Câmara dos Deputados e uma pelo Senado Federal, culminando na versão aprovada pelo Congresso em dezembro de
2013, que deu origem à Lei No 12.897 (BRASIL, 2013).

A negociação da FASER permitiu que a composição do Conselho de Administração fosse ampliada, determinando-se que seja integrado pelo Presidente da ANATER, Presidente da EMBRAPA, quatro representantes do Poder Executivo federal, um representante de governos estaduais e quatro representantes de entidades de produtores rurais, sendo estes um representante da CONTAG, um representante da Federação Nacional dos Trabalhadores e Trabalhadoras na Agricultura Familiar (FETRAF), um representante da CNA e um representante da Organização das Cooperativas Brasileiras (OCB). Portanto, respectivamente duas entidades representantes dos trabalhadores rurais e duas representantes da classe patronal.

No entanto, apesar de na estrutura organizacional encontrar-se prevista uma Diretoria de ATER, responsável pela Gerência de Monitoramento e Avaliação dos serviços de ATER e pela Gerência de Fomento à Assistência Técnica, passou a ser responsabilidade da EMBRAPA, através de sua Diretoria de Transferência de Tecnologia, realizar em estreita colaboração com a ANATER a integração do sistema de pesquisa agropecuária e do sistema de assistência técnica e extensão rural, competindo-lhe a geração de tecnologias, a validação de seus métodos de transferência e a capacitação de seus multiplicadores. Ademais, em relação ao público beneficiário, foram incluídos os médios produtores rurais.

Neste sentido, a criação da ANATER retirou em grande parte a centralidade do MDA no processo de qualificação dos profissionais de ATER no país, que vem ocorrendo principalmente através de chamadas públicas conjuntas com o $\mathrm{CNPq}$, concebidas através do diálogo entre este órgão, o movimento agroecológico, os movimentos sociais do campo e a rede de ATER estruturada durantes as décadas de 1990 e 2000.

No entanto, após a criação da ANATER, em diversos fóruns da Sociedade Civil organizados por entidade públicas e privadas de ATER estiveram presentes seu presidente nomeado pela presidente Dilma Roussef e demais membros do conselho gestor, composto em 2015. Nestes espaços, foram reelaborados compromissos de gestão da ANATER baseados na PNATER e debatidas as críticas apresentadas pelo CONDRAF em relação às medidas necessárias à universalização, de fato, e à melhoria da qualidade dos serviços de ATER. Em certa medida, portanto, a diretoria executiva da ANATER demonstrou abertura e capacidade de diálogo com a Sociedade Civil organizada e movimentos sociais do campo, historicamente ligados 
e responsáveis pela concepção da PNATER

Em 2016, no entanto, o presidente da ANATER nomeado pela Presidente Dilma Roussef foi exonerado de seu cargo por Michel Temer, apesar de mandato de quatro ano garantido pelo Lei de criação da ANATER. Desde então, a ANATER se afastou dos debates públicos de ATER e do CONDRAF, sem que haja margem para diálogo junto a seus representantes. A tendência é que, neste novo contexto, a ATER pública retorne as suas origens do produtivismo difusionista, voltada a atender um modelo de desenvolvimento rural que priorizará interesses patronais e, mais uma vez, marginalizará agricultoras e agricultores familiares no acesso a serviços de ATER.

\section{Considerações Finais}

Não podemos prever o futuro. Porém, analisar de forma sistematizada o passado nos permite a identificação de processos similares no presente e, desta maneira, relacioná-los a previsíveis desfechos. No campo de estudos das políticas públicas esta é uma importante ferramenta para que gestores públicos, movimentos sociais e outros grupos da Sociedade Civil organizada possam reunir informações, comparar pontos de vistas e subsidiar criticamente seus processos decisórios.

No caso brasileiro se faz ainda mais fundamental empreender tal exercício. Isto porque, por um lado, trata-se de uma sociedade em que a experiência democrática pode ser considerada relativamente recente e, por outro, permanecem sob ameaças de retrocesso uma série de direitos sociais e acesso a serviços públicos conquistados por grupos historicamente excluídos. Nesse sentido, trataremos especificamente do caso da ANATER e dos prenúncios que sua implementação impõem ao modelo de ATER voltado exclusivamente à agricultura familiar.

A partir do regaste exposto neste trabalho, é possível afirmar que as atividades relacionadas à pesquisa, ensino, assistência técnica e extensão para o meio rural foram marcadas pelos esforços estatais em atender às demandas das elites agrárias nacionais, por meio do estreito alinhamento de subsequentes gestões governamentais a projetos de desenvolvimento que, deliberadamente, contribuíram para a perpetuação da concentração de rendas e terras no campo brasileiro. Dentre os atores centrais deste processo cabe destacar o papel do MAPA, âncora da promoção e consolidação de um modelo de modernização agrícola convencional, pautado na produção agroexportadora e especializada, através de políticas públicas de crédito, assistência técnica, produção e transferência de tecnologias que historicamente privilegiaram uma minoria de produtores altamente capitalizados e detentores de grandes propriedades.

Ao longo dos quase dois séculos abordados neste trabalho, cabem destacar dois momentos que marcaram importantes rupturas hegemônicas no que diz respeito às diretrizes e público beneficiário dos serviços públicos de ATER. O primeiro se deu entre 1985 e 1990, quando gestores da extinta EMBRATER passaram a pautar publicamente a necessidade de uma ATER voltada aos agricultores de base familiar, tomando por referência o humanismo crítico. E, na mesma perspectiva, o segundo momento se deu a partir de 2003, com a transferência da coordenação dos serviços públicos de ATER do MAPA para o MDA, o qual, através da ampla participação da sociedade civil vem consolidando um modelo de ATER que busca promover a soberania dos agricultores familiares, por meio da redução do uso de tecnologias que geram dependência contínua e aumentam custos de produção, relações de mercado mais equitativas e da construção horizontal do conhecimento.

Cabe ressaltar que, como visto, o MDA foi criado em meados da década de 1990 numa conjuntura de forte pressão política dos movimentos sociais do campo e organizações da Sociedade Civil ligadas a correntes progressistas, que pautavam tanto uma Reforma Agrária de fato redistributiva e profunda, como políticas de crédito, pesquisa e extensão voltadas aos agricultores familiares. Neste sentido, desde então passou a representar um projeto de desenvolvimento rural concorrente ao levado a cabo historicamente pelos programas dos Ministérios da Agricultura.

No entanto, foi apenas a partir de 2003, no governo do Partido dos Trabalhadores, que o MDA passou a dispor dos recursos humanos e materiais que lhe permitiram fazer jus a suas origens, por meio do estabelecimento e ampliação de fóruns e canais de participação social através dos quais são concebidas, planejadas e operacionalizadas suas políticas. Desde então, estes esforços se materializaram nas versões da PNATER, PRONATER e no modelo de gestão descentralizado do atual SIBRATER, que, apesar das críticas e limitações apontadas neste resgate, vinha concretizando o fortalecimento de uma rede de ATER nacional junto aos movimentos sociais, entidades estaduais de ATER, ONGs, associações e cooperativas de agricultores familiares e Universidades.

A partir de 2010, assim como o foi no fim da década de 1980, cresceram as ameaças às conquistas da ATER pública no país. No caso da EMBRATER, 
foi o Congresso Nacional que impediu sua extinção durante o governo Sarney por meio de decreto legislativo, mas também que, já majoritariamente conservador, apoiou sua extinção no Governo Collor. No caso do MDA, a partir especialmente de 2014 é o Executivo Federal que vem enfrentando sucessivas investidas tanto do Congresso Nacional, mais à direita do que nas gestões anteriores do Partido dos Trabalhadores, como de membros do alto escalão do governo ligados a partidos conservadores de sua base aliada. Em 2016, o MDA foi então extinto por Michel Temer após o afastamento da presidente eleita, Dilma Roussef.

Vale relembrar que a proposta de criação de um novo órgão federal de ATER surgiu da avaliação da Rede nacional de ATER após a primeira CNATER, em 2012. Originalmente, visava-se o fortalecimento e dinamização do SIBRATER por meio da criação de um órgão que dialogasse como seu modelo de gestão e não sua repartição de competências ou profunda reestruturação, como proposto no modelo visado pela ANATER.

Destacamos outra similaridade relacionada à concepção da ANATER via MAPA no contexto atual e no cenário da Operação Desmonte do governo Sarney, quando ocorreram sucessivas tentativas de fusão entre a EMBRAPA e a EMBRATER, levando à extinção da última no governo Collor. Em ambos os casos, ocorreu a crescente projeção no interior do Estado de uma instituição que representa a contra hegemonia dos interesses de grupos patronais. Em sequência, foram apropriadas importantes políticas destes órgãos de ATER pelo MAPA, através da EMBRAPA. No primeiro caso, toda a gestão do SIBRATER foi transferida e, no caso atual, foi atribuída a responsabilidade pela formação de multiplicadores e de integração da pesquisa e extensão ao Departamento de Transferência de Tecnologia da EMBRAPA.

A gestação da ANATER e sua implementação apresenta uma série de preocupações à rede de ATER, movimentos sociais e movimento agroecológico que compõem o SIBRATER. Dentre estas, as principais são relativas à inclusão dos médios produtores no público beneficiário e à centralidade atribuída ao Departamento de Transferência de Tecnologia da EMBRAPA na integração entre pesquisa, extensão e formação de multiplicadores.

Esta preocupação procede, uma vez que o Departamento de Transferência de Tecnologia da EMBRAPA se demonstrou incapaz de atuar como receptor das demandas das entidades de ATER estaduais, ONGs e movimentos sociais nos anos subsequentes à extinção da EMBRATER, tendo sido o SIBRATER desmantelado durante a década de 1990. Ademais e ainda mais preocupante é o fato de que a rede de ATER que se consolidou no país ao longo das décadas de 1990 e 2000 o fez de maneira independente às ações do MAPA e EMBRAPA.

Mais recentemente é possível afirmar também que a EMBRAPA teve inexpressiva atuação na construção da PNATER e do atual modelo de gestão do SIBRATER. Por outro lado, e sem dúvida alguma, encontramos no sistema EMBRAPA iniciativas e pesquisadores comprometidos com o compartilhamento e a geração de conhecimentos e tecnologias baseados no protagonismo dos agricultores familiares em diferentes regiões do país. No entanto, desde sua concepção, as principais atividades da Empresa vêm sendo condicionadas à geração e transferência vertical de tecnologias voltadas a uma parcela restrita de produtores rurais, especialmente os médios e grandes, assim como o foram predominantemente orientadas pelo difusionismo produtivista da modernização agrícola das décadas de 1970 e 1980. Por este motivo, ainda hoje, é possível afirmar que a EMBRAPA não desfruta do savoir-faire necessário à gestão participativa e formação de quadros para os serviços de ATER pública.

Por fim, a proposta de disseminação de tecnologias e treinamento de multiplicadores via EMBRAPA, explicitada no modelo de coordenação dos serviços de ATER proposto para a ANATER, representa um retrocesso em relação à conquista de uma ATER gratuita, pública e voltada à agricultura familiar, numa perspectiva crítica, emancipatória e empoderadora deste ator social. A exoneração de seu presidente incialmente nomeado aponta para a concretização dos riscos anteriormente identificados pelos atores que compõem a rede de ATER, uma vez que, apesar de todas as críticas direcionadas à ANATER, vinha demonstrando, assim como o Conselho Gestor, a capacidade de priorizar pelo diálogo e participação social que marcaram a construção e ganhos sociais da PNATER.

Deste modo, concluímos que a implementação da ANATER apresenta elevado risco à consolidação de um desenvolvimento rural que permita, de fato, à agricultura familiar desfrutar do protagonismo que the foi historicamente negado. Caberá aos movimentos sociais do campo e entidades da Sociedade Civil a construção de novos espaços e estratégias para que a PNATER não se torne uma experiência de política pública resguardada ao passado da história brasileira, apesar da conjuntura política de afastamento do governo do Partido dos Trabalhadores do executivo federal. E, por outro lado, lhes caberá também a luta para que a ANATER seja implementada 
de acordo com os interesses daqueles grupos que viabilizaram a conquista de sua criação.

\section{Referências Bibliográficas}

BRASIL. Política Nacional de Assistência Técnica e Extensão Rural para a Agricultura Familiar e Reforma Agrária - PNATER e o Programa Nacional de Assistência Técnica e Extensão Rural na Agricultura Familiar e na Reforma Agrária - PRONATER. Brasília: MDA, 2010.

. Lei 12.188, de 11 de janeiro de 2010. Institui a Política Nacional de Assistência Técnica e Extensão Rural para a Agricultura Familiar e Reforma Agrária - Pnater e o Programa Nacional de Assistência Técnica e Extensão Rural na Agricultura Familiar e na Reforma Agrária - Pronater, altera a Lei no 8.666, de 21 de junho de 1993, e dá outras providências. Diário Oficial da República Federativa do Brasil, Poder Executivo, Brasília, DF, 12 jan. 2010.

Lei $\mathbf{n}^{0}$ 12.897, de 18 de dezembro de 2013. Autoriza o Poder Executivo federal a instituir serviço social autônomo denominado Agência Nacional de Assistência Técnica e Extensão Rural - ANATER e dá outras providências. Diário Oficial da República Federativa do Brasil, Poder Executivo, Brasília, DF, 20 dez. 2013.

BERGAMASCO, S. M. P. P; Agricultura e Assistência Técnica no Estado de São Paulo. Botucatu: Faculdade de Ciências Agronômicas do "Campus" de Botucatu (UNESP), 1983. 286p. (Tese de Livre-Docência).

BRANDENBURG, A. Movimento Agroecológico: trajetória, contradições e perspectivas. Desenvolvimento e Meio Ambiente, n.6, p. 11-28, 2002. BRASIL. Ministério do Desenvolvimento Agrário. Política Nacional de Assistência Técnica e Extensão Rural. Brasília: MDA, 2004

CAPORAL, F. R. Lei de ATER: exclusão da Agroecologia e outras armadilhas. Cadernos de Agroecologia, Cruz Alta, v. 6, n. 2, p.1-7, dez, 2011.
DINIZ, P. C. O.; LIMA, J. R. T.; ALMEIDA, A. Chamadas públicas de ATER: primeiras reflexões. In: Congresso Internacional da Associação Latinoamericana De Sociologia, 28., 2011, Recife. Anais eletrônicos... Recife: UFPE, 2011.

ENCONTRO INTERnACIONAL DE AGROECOLOGIA. Moção de repúdio ao processo de criação e concepção da ANATER. Disponível em < http://www.eiabotucatu2013.blogspot.com.br/p/mocao-de-repudioao-processo-de.html>. Acesso em 02 de agosto de 2015.

LUZZI. N. O debate agroecológico brasileiro: uma discussão a partir dos EBAAS e da experiência do PTA/FASE. 182f. Tese (Doutorado em desenvolvimento, agricultura e sociedade) - Universidade Federal Rural do Rio de Janeiro, Rio de Janeiro, 2007. Disponível em: < http://orgprints. org/21839/1/Luzzi_Debate.pdf>. Acesso em: 10 jul. 2014.

MACHADO, L. T. Formação do Brasil e Unidade Nacional. São Paulo: IBRASA, 1980. 286p.

MDA/SAF/DATER. Política Nacional de Assistência Técnica e Extensão Rural. Ministério do Desenvolvimento Agrário (MDA), Secretaria de Agricultura Familiar (SAF), Grupo de Trabalho Ater, 2004, 22p. Disponível em: http://www.pronaf.gov.br/dater/arquivos/Politica\%20Nacional\%20 de\%20ATE R.pdf. Acesso em 18 de mar de 2015.

Relatório Final do Seminário Nacional de Ater. 2008. Brasília-DF. Disponível em: http://www.deser.org.br/publicacoes/ Sistematiza\%E7\%E3o\%20final.pdf. Acesso em: 20 de mar de 2015.

OLINGER, G. Ascensão e decadência da extensão rural no Brasil. Florianópolis : EPAGRI, 1996, 523 p.

OLIVEIRA, M. M. As circunstâncias da criação da extensão rural no Brasil. Brasília : EMBRAPA/SCT. Cadernos de Ciência \& Tecnologia, Brasília, v.16, n.2, p.97-134, maio/ago. 1999.

PASSOS GUIMARÃES, A. Quatro séculos de latifúndio. Rio de Janeiro: Paz e Terra, 1968. 
PEIXOTO, M. Extensão Rural no Brasil - Uma abordagem histórica da legislação. [Textos para discussão, n.48] Brasília: Consultoria Legislativa do Senado Federal - Centro de Estudos, outubro/2008. Disponível em: $<$ http:// www.senado.gov.br/senado/conleg/textos_discussao/TD48-MarcusPeixoto. pdf $>$. Acesso em: 18 de mar de 2015.

PETTAN, K. B. A Política Nacional de Assistência Técnica e Extensão Rural (PNATER): Percepç̃es e Tendências. 2010. 393 f. Tese (Doutorado em Engenharia Agrícola na área de concentração em Planejamento e Desenvolvimento Rural Sustentável)-Universidade Estadual de Campinas, São Paulo, 2007. Disponível em: $<$ http://www.bibliotecadigital.unicamp. br/document/>. Acesso em: 04 de mar de 2015.

PRADO JÚNIOR, C. História econômica do Brasil. São Paulo: Brasiliense, 1945.

RIBEIRO, J. P. A saga da extensão rural em Minas Gerais. São Paulo: Annablume: Belo Horizonte: CPP/Emater-MG, 2000. 270p.

RODRIGUES, C. M. Conceito de seletividade de políticas públicas e sua aplicação no contexto da política de extensão rural no Brasil. Cadernos de Ciência e Tecnologia, Brasília, v.14, n.1, p.113-154, 1997.

SEMINÁRIO NACIONAL DE ASSISTENCIA TÉCNICA E EXTENSÃO RURAL, 1997, Brasília, DF. Anais... Brasília, DF: PNUD, 1997.

WORKSHOP nacional "Uma nova assistência técnica e extensão rural centrada na agricultura familiar”, 1997. Brasília: PNUD, 1997. 47p.

IAEN, Quito, 2014, p.19-34.Fonte: Assunção 2016

\section{FUNCユ̃̃O SOCIAL DA PROPRIEDADE: O AMBIENTAL E O ECONÔMICO NA QUESTÃO DA DESAPROPRIAÇÃO AGRÁRIA}

Monyele Camargo Graciano Leandro de Lima Santos

Resumo: Este trabalho traz uma análise a respeito do cumprimento do princípio constitucional da função social da propriedade rural e da insuscetibilidade da propriedade produtiva no processo de desapropriação para fins de reforma agrária. O objetivo da pesquisa foi verificar por meio de decisões extraídas dos Tribunais Federais, a interpretação jurisprudencial do efetivo cumprimento da função ambiental dos imóveis rurais, diante do imperativo constitucional do artigo 185, II, da Constituição Federal. Ao analisar as legislações e os casos julgados, percebe-se que as decisões citadas foram fundamentadas, majoritariamente, a partir dos índices de produtividade excetuando-se ao cumprimento da função ambiental da propriedade rural, preconizado no artigo 186 do texto constitucional, que é condição simultânea para o cumprimento da função social da propriedade, sob pena de desapropriação.

Palavras-chave: Função Social da Propriedade; Proteção Ambiental; Produtividade de Imóveis Rurais.

Abstract:This paper presents an analysis of the compliance with the constitutional principle of the social function of rural property and the insusceptibility of productive property in the expropriation process for agrarian reform purposes. The objective of the research was to verify, through decisions taken from the Federal Courts, the jurisprudential interpretation of the effective fulfillment of the environmental function of rural properties, in view of the constitutional imperative of article 185, II, of the Federal Constitution. In analyzing the legislation and the cases judged, it can be seen that the decisions cited were mainly based on productivity indexes, except for the environmental function of rural property, as recommended in article

Mestre em Agronegócio pela Universidade Federal de Goiás/ e-mail: monyelecamargo@gmail.com 2 Doutor em Sociologia pela Universidade Federal de Goiás. Professor Adjunto da Universidade Federal de São Carlos - UFSCar/ e-mail: leandrodelima@ufscar.br 